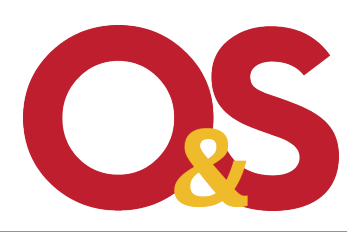

Revista Organizações \& Sociedade

2020, 27(92), $11-14$

EDITORIAL

(1) Autor(es) 2020

\title{
Que sociedade? Que teorizações?
}

DOI 10.1590/1984-9270920

Which society? Which theorizations?

ISSN 1984-9230

www.revistaoes.ufba.br

NPGA, Escola de Administração

Universidade Federal da Bahia

\author{
Eduardo Paes Barreto Davel ${ }^{a}$ \\ Marcelo de Souza Bispo ${ }^{b}$ \\ Claudia Simone Antonelloc \\ aniversidade Federal da Bahia, Salvador, BA, Brasil \\ universidade Federal da Paraíba, João Pessoa, PB, Brasil \\ Universidade Federal do Rio Grande do Sul, Porto Alegre, RS, Brasil
}

\section{RESUMO}

De qual sociedade falamos quando pensamos em Organizações \& Sociedade? Falamos da sociedade reconhecida pelo pesquisador como contexto plural, heterogêneo e enigmático. Cada sociedade a cada momento histórico nos instiga a renovar nossas formas de conhecê-la e sobre ela teorizar. 0 trabalho de teorizar é muito exigente, sobretudo em nosso contexto nacional, por causa de nossa tradição em não formar mestres e doutores voltados para enfrentar a tarefa e o esforço de teorizar. Essa fragilidade de teorização evidencia não apenas nossos problemas e desafios enquanto pesquisadores, ela reflete também na nossa prática educacional, especialmente a prática da pós-graduação.

Palavras-chave: Organização; Sociedade; Teorização.

\section{ABSTRACT}

Which society do we talk about when thinking on Organizations \& Society? We speak of the society recognized by the researcher as a plural, heterogeneous, and enigmatic context. Each society and organization at each historical moment encourages us to renew our ways of knowing and theorizing about it. The work of theorizing is very demanding, especially in our national context, because of our tradition of not training masters and doctors focused on facing the task and the effort of theorizing. This theorizing weakness highlights not only our problems and challenges as researchers, it also reflects on our educational practice, especially the practice of graduate schools.

Keywords: Organization; Society; Theorization. 
A tradição da O\&S consiste em abordar temas originais na área de Administração e dos Estudos Organizacionais. Com isso, a revista ofereceu espaço para uma abertura de reflexões sobre como diversos tipos de organizações e fenômenos organizacionais se relacionam dentro do contexto das sociedades nas quais estão inseridas. Esse número da O\&S nos convida a avançar no entendimento das transformações recentes que acontece nas sociedades do mundo, desde a "Primavera Árabe" (Visentini, 2012), passando pelas manifestações sobre o "Brexit" (Beech, 2020), os "coletes amarelos" na França, os confrontos na América Latina, especialmente no Chile, a polaridade política que se estabeleceu no Brasil, e a pandemia do coronavirus, nos tempos recentes (Machado \& Miskolci, 2019). No seu conjunto, são acontecimentos que laçam um desafio não apenas para os cientistas sociais, mas também para nós, cientistas da Administração e dos Estudos Organizacionais, porque eles refletem nas maneiras pelas quais as organizações realizam suas práticas cotidianas.

Como qualquer fenômeno organizacional que encontra-se entranhado em seu contexto, somos demandados a gerar novas teorizações para refletir sobre as mudanças em andamento (Swedberg, 2014; Weick, 1995) e tornar os resultados da pesquisa mais inovadores e relevantes (Alvesson \& Sandberg, 2013; Flyvbjerg, 2006). O trabalho de teorizar é muito exigente, sobretudo em nosso contexto nacional, por causa de nossa tradição em não formar mestres e doutores voltados para enfrentar a tarefa e o esforço de teorizar. Teorizar significar lidar com mistérios (Alvesson \& Kärreman, 2007; 2011) para criar com sistemática, rigor, contexto e criatividade. Teorizar implica em correr riscos e em ter que lidar com eventuais fracassos. Por isso, outra causa da dificuldade em teorizar em nossas pesquisas explica-se devido ao condicionamento recorrente ao mimetismo - resquício da colonização das sociedades do hemisfério norte na produção científica global - que sedutoramente nos incita a pegar o caminho mais fácil de reproduzir e aplicar teorias alheias. Esse mimetismo sedutor, além de se apresentar em um trabalho mais acomodado, nem sempre permite explicar com fineza nossos contextos imediatos: brasileiro e latino-americano (Ger, Suarez \& Nascimento, 2019).

Essa fragilidade de teorização evidencia não apenas nossos problemas e desafios enquanto pesquisadores. Ela reflete também na nossa prática educacional, especialmente a prática da pós-graduação. Espera-se que futuros mestres e doutores sejam capazes de interpretar cenários complexos e diversos, produzindo respostas na forma de conhecimentos originais, robustos e sensíveis ao contexto contemporâneo, que vão desde a escala local até a escala global (Silver, 2019). Consequentemente, como professores, nosso propósito é formar pesquisadores, teoricamente e metodologicamente, criativos, reflexivos, relevantes e rigorosos. Seja exercendo o trabalho de pesquisar para teorizar, seja ensinando outros a como exercer esse trabalho, não devemos desconsiderar o papel que a política e o engajamento social desempenham no processo (Alvesson \& Sköldberg, 2000; Becker, 1993; Cunliffe \& Scaratti, 2017; Van de Ven, 2007). Pesquisar e teorizar sobre fenômenos humanos e sociais exige um engajamento sociopolítico para conseguirmos alcançar as sutilezas, relevâncias e singularidades de seus contextos.

De qual sociedade falamos quando pensamos em Organizações \& Sociedade? Falamos da sociedade reconhecida pelo pesquisador como contexto plural, heterogêneo e enigmático. Cada sociedade a cada momento histórico nos instiga a renovar nossas formas de conhecê-la e sobre ela teorizar. Temos compromisso com a nossa contemporaneidade e atuamos por meio de questionamentos, construções teóricas e metodológicas, em um permanente movimento reflexivo, propositivo e de renovação. Propomos uma visão trans e interdisciplinar para a realização de estudos que contemplem as múltiplas realidades engendradas pela e na sociedade e suas interfaces com as organizações.

Com efeito, o futuro da O\&S - os artigos que Ihe serão submetidos e publicados - deve refletir esta postura científica para que a revista continue não apenas sendo de vanguarda acadêmica, mas que possibilite ampliar e aprofundar o diálogo com as sociedades as quais alcança. Ou seja, espera-se que os artigos publicados possam gerar orientação frente aos problemas atuais, servindo de referência para o contínuo debate entre diferentes posições políticas, filosóficas e teóricas. Essa postura reflete também as várias transformações que a revista passa: (a) renovação do conselho editorial e do padrão de publicação, (b) orientação progressiva para a internacionalização e (c) busca de contribuições com relevância explícita no âmbito conceitual e teórico. Além 
disso, instauramos uma editoria colegiada e especializada, com a participação de editores associados. Como este editorial, os próximos vão refletir essa vontade de realizar uma editoria coletiva e compartilhada. Outra transformação refere-se a tornar a revista cada vez mais presente nas redes sociais e acessível em língua inglesa. Buscamos fortalecer nossa difusão e nossa relevância ao gerar um espaço mais amplo de interação nos meios contemporâneos de comunicação. Consequentemente, buscaremos integrar fotos e vídeos na produção de nossos autores para melhor animarmos esse espaço.

As transformações que ocorrem na O\&S não a distanciam de sua identidade. Pelo contrário, a revista está cada vez mais centrada no que sempre foi sua vocação: publicação de pesquisa multidisciplinar, interdisciplinar, criativa, crítica, teoricamente orientada, internacional e não tradicional, enraizada em uma ampla variedade de disciplinas, inspirada pela diversidade, aberta à pluralidade epistemológica e metodológica. 0 foco permanece na publicação de pesquisas que agreguem valor à sociedade e que sejam socialmente significativas.

\section{Referências}

Alvesson, M., \& Kärreman, D. (2007). Constructing mystery: empirical matters in theory development. Academy of Management Review, 32(4), 1265-1281.

Alvesson, M., \& Kärreman, D. (2011). Qualitative research and theory development: mystery as method. Los Angeles: SAGE.

Alvesson, M., \& Sandberg, J. (2013). Has Management Studies Lost Its Way? Ideas for More Imaginative and Innovative Research. Journal of Management Studies, 50(1), 128-152.

Alvesson, M., \& Sköldberg, K. (2000). Reflexive methodology: new vistas for qualitative research. London: Sage Publications.

Becker, H. S. (1993). Métodos de pesquisa em Ciências Sociais. São Paulo: Editora Hucitec.

Beech, M. (2020). Brexit and the decentred state. Public Policy and Administration. Special Issue: Decentred State(February), 1-17.

Cunliffe, A. L., \& Scaratti, G. (2017). Embedding Impact in Engaged Research: Developing Socially Useful Knowledge Through Dialogical Sensemaking. British Journal of Management, 28(1), 22-44.

Flyvbjerg, B. (2006). Making organization research matter: power, values and phronesis. In S. R. Clegg, C. Hardy, T. B. Lawrence, \& W. R. Nord (Eds.), The SAGE Handbook of organization studies. London: Sage Publications.

Ger, G., Suarez, M. C., \& Nascimento, T. C. D. (2019). Context and Theorizing in the Global South: Challenges and Opportunities for an International Dialogue. Brazilian Administration Review, 16(3), 1-18, e180069.

Machado, J., \& Miskolci, R. (2019). Das Jornadas de junho à cruzada moral: o papel das redes sociais na polarização política brasileira. Sociologia \& Antropologia, 9(3), 945-970.

Silver, D. (2019). Theorizing Is a Practice, You Can Teach It. Canadian Review of Sociology, 56(1), 130-133.

Swedberg, R. (Ed.) (2014). Theorizing in Social Science: The Context of Discovery. Stanford: Stanford University Press.

Van de Ven, A. H. (2007). Engaged scholarship: a guide for organizational and social research. Oxford: Oxford University Press.

Visentini, P. F. (2012). A Primavera Árabe: entre a democracia e a geopolítica do Petróleo. Porto Alegre: Editora Leitura XXI.

Weick, K. E. (1995). What theory is not, theorizing is. Administrative Science Quarterly, 40(3), 385-390. 


\section{Sobre os Autores}

\section{Eduardo Paes Barreto Davel}

Professor na Escola de Administração da Universidade Federal da Bahia. Pós-doutor em Administração pela Nova School of Business and Economics da Universidade Nova de Lisboa (Portugal) e Ph.D. em Administração pela École des Hautes Études commerciales de Montreal (Canadá). Editor-chefe da revista Organizações \& Sociedade. Pesquisa e publica sobre empreendedorismo cultural, gestão do processo criativo, ensino, metodologia, aprendizagem, cultura e estética nas organizações. E-mail: davel.eduardo@gmail.com. ORCID: 0000-0003-0610-6474

\section{Marcelo de Souza Bispo}

Professor do Departamento de Administração e co-líder do Núcleo de Estudos em Aprendizagem e Conhecimento (NAC-UFPB) da Universidade Federal da Paraíba. Realizou estágio pós-doutorado na Universidade de Kentucky (EUA) e doutorado em Administração pela Universidade Presbiteriana Mackenzie. Editor Associado da revista Organizações \& Sociedade para o eixo Organizações e Educação. Seus interesses de pesquisa são sobre teoria organizacional, educação e turismo. E-mail: marcelodesouzabispo@gmail.com. ORCID: 0000-0002-5817-8907

\section{Claudia Simone Antonello}

Professora na Escola de Administração da Universidade Federal do Rio Grande do Sul. Editora Associada da revista Organizações \& Sociedade para o eixo Organizações, Aprendizagem e Conhecimento. Doutora em Administração pela Universidade Federal do Rio Grande do Sul. Pesquisa e publica sobre aprendizagem nas organizações, abordagens críticas, não ortodoxas, relacionadas a constituição de saberes, de práticas e do trabalho na sociedade contemporânea. E-mail: claudia.antonello@ufrgs.br. ORCID: 0000-0001-9654-5125 